\title{
O NEGACIONISMO DO HOLOCAUSTO: pseudo-história e história pública
}

\section{The Holocaust Denial: pseudohistory and Public History}

\author{
Ricardo Figueiredo de Castro* \\ ricardocastro@ufrj.br
}

Resumo

O Holocausto é um dos temas mais tratados pela História Pública, mas uma forma de pseudo-história, o Negacionismo do Holocausto contamina o debate público em torno do assunto com um discurso de ódio, maniqueísta e antissemita que é usado pela extrema-direita contemporânea como um elemento de coesão ideológica e, simultaneamente, como uma estratégia de tentar se viabilizar politicamente por meio da negação dos crimes contra a humanidade cometidas pelo regime Nacional-Socialista alemão.

Palavras-chave: antissemitismo, Negacionismo do Holocausto, pseudo-história.

\begin{abstract}
The Holocaust is one of the most discussed topics in Public History. However, a form of pseudohistory, Holocaust Denial, contaminates the public debate around the subject with anti-semitic and manicheistic hate-speech, which is used by the contemporary far-right simultaneously as an ideological cohesion element and a strategy of trying to enable itself politically through the denial of crimes against humanity committed by the German National Socialist regime.
\end{abstract}

Keywords: pseudo-history, Holocaust Denial, antisemitic.

* Historiador. Doutor em História pela Universidade Federal Fluminense (UFF). Professor de História Contemporânea do Instituto de História (IH) da Universidade Federal do Rio de Janeiro (UFRJ). Pesquisador do Laboratório de Estudos do Tempo Presente (TEMPO). 
Artigos

O genocídio dos judeus na II Guerra Mundial talvez seja um dos temas mais tratados pelos diferentes ramos da História Pública neste início do século XXI. Museus tradicionais e virtuais ${ }^{1}$, websites ${ }^{2}$, revistas de divulgação científica, documentários, exposições ${ }^{3}$, palestras, entre outros, dedicam-se a resgatar e preservar a memória e a divulgar o estado atual do conhecimento histórico acumulado pela historiografia do Holocausto.

O Memorial and Museum Auschwitz-Birkenau ${ }^{4}$, por exemplo, localizado no complexo de campos de concentração de mesmo nome transformou-se num museu a céu aberto que recebe milhares de visitantes por ano e que, por meio do contato dos visitantes com a materialidade do Holocausto, pretende manter unidos os pontos da trama da memória coletiva a respeito desse inacreditável evento.

A história e a memória de uma sociedade não são debatidas apenas pelos historiadores. Apesar de frequentemente os historiadores serem questionados sobre a relevância e a utilidade do trabalho historiográfico, a história e a memória são a base de diferentes questões colocadas pelos cidadãos e instituições, especialmente nos assuntos e nos problemas relacionados ao poder, posto que a política está intimamente ligada, embasada em questões históricas.

Entretanto, nem sempre esta demanda é suprida pelo acesso à historiografia produzida pelos historiadores com formação acadêmica na disciplina e divulgada nos diferentes veículos de comunicação aos quais os historiadores têm acesso. Frequentemente, o que acontece é a produção de textos elaborados por pessoas de diferentes formações universitárias, como por exemplo, jornalistas, que oferecem produtos culturais que se adequam mais facilmente às exigências do mercado editorial e midiático.

Com o avanço e o aprofundamento do processo de "midiação da cultura moderna", no último quarto do século XX, o papel ideológico exercido por estes produtos culturais (livros, websites, revistas, programas de TV etc.) tem se aprofundado e se consolidado como uma importante forma de produção cultural, competindo com a produção historiográfica disseminada sob a forma de "divulgação científica".

No entanto, interessa-nos aqui um tipo particular desse tipo de produto "historiográfico", aquele que é denominado pelos membros do movimento cético estadunidense (Skeptic Society) como pseudo-história, isto é, textos que, entre outras características, consideram-se portadores de uma missão em prol da defesa de alguma plataforma política ou religiosa manipulando a escolha e a análise de referências bibliográficas e fontes primárias para a confirmação da tese que se quer confirmar.

Existem atualmente diferentes exemplos de pseudo-história, tais como a "Nova Cronologia", o "Afrocentrismo", a "Teoria do Antigo Astronauta". Cada uma dessas correntes pseudo-historiográficas tem atualmente um vasto público consumidor de seus produtos culturais e midiáticos. O matemático russo Anatoli Fomenko, por exemplo, um dos atuais disseminadores da chamada "Nova Cronologia" é popular em seu país e já vendeu milhares de cópias de suas obras. ${ }^{6}$

Uma das principais correntes pseudo-historiográficas é a do Negacionismo do Holocausto (Holocaust Denial - Négation de la Shoah - Holocaustleugnung - Negazionismo dell'Olocausto) que há décadas produz uma série de textos que se dedicam a provar que o Holocausto não existiu.

Assim, as atividades da História Pública em relação ao Holocausto são contaminadas pela atuação militante daqueles que se dedicam a minimizar ou a negar a existência do Holocausto.

Estas pessoas integram um movimento político e ideológico que afirma resgatar a verdadeira história da II Guerra Mundial que estaria sendo deturpada pela "história oficial", dedicada a esconder os "verdadei-

1 Tais como o United States Memorial Holocaust Museum em Washington, bem como outros em diferentes cidades estadunidenses. No Brasil, já existe um museu especializado no Holocausto em Curitiba (http://www.museudoholocausto.org.br/) e há previsão de um museu do Holocausto em São Paulo. Todos esses museus têm sua website.

2 Tais como o holandês Dutch Auschwitz Comitee (http://www.auschwitz.nl/englishprojet), o brasileiro Arquivo Virtual ArqShoah Holocausto e Antissemitismo (http://www.arqshoah.com.br/) e o projeto liderado pelo padre francês Patrick Debois que se dedica a coletar e a preservar os depoimentos das pessoas de presenciaram assassinatos coletivos de judeus no Leste Europeu, disponível no site http://www.yahadinunum.org/.

3 Disponível em: http://www.memorialdelashoah.org/upload/minisites/ukraine/exposition1.htm

4 Disponível em: http://en.auschwitz.org/m/

5 “(...) a proliferação rápida de instituições e meios de comunicação de massa e o crescimento de redes de transmissão através dos quais formas simbólicas mercantilizadas se tornaram acessíveis a um grupo cada vez maior de receptores” Cf. THOMPSON (1995: 21)

6Cf.overbete "New Chronology"naWikipedia.Disponívelem: http://en.wikipedia.org/wiki/New_Chronology_\%28Fomenko\%29\#cite note-30. Acesso em 20 de outubro de 2014. 
ros" responsáveis pela guerra, os aliados, e a incriminar os alemães e, por extensão, os nazistas. Proclamam-se integrantes de um movimento autodenominado Revisionismo do Holocausto, mas os historiadores chamam este movimento de Negacionismo do Holocausto. Atualmente, eles disseminam suas ideias principalmente por intermédio da Internet por meio de incontáveis websites institucionais e pessoais, listas de discussão, redes sociais etc. Dessa forma, diferentemente do que acontecia até meados dos anos 1990, atualmente o material negacionista está acessível diretamente a qualquer pessoa com acesso à rede mundial de computadores e em diferentes línguas.

Para tornar ainda mais confuso esse quadro, a maior livraria virtual do mundo, a Amazon.com, vende material negacionista, antissemita e racista com obras acadêmicas sobre o Holocausto ${ }^{7}$. Além disso, sabendo que a Internet se tornou a principal ferramenta de pesquisa entre os jovens, os negacionistas dedicam-se a criar condições para que seus websites ocupem as principais posições nas pesquisas feitas nos buscadores, tais como o Google.

Para demonstrarmos como esse tema é relevante para as discussões sobre a História Pública, poderemos citar a pesquisa recentemente divulgada (2014) pela Anti-Difamation League. ${ }^{8}$ Ela entrevistou pessoas em cem países em todos os continentes e concluiu que "apenas 33\% das pessoas conscientes da existência do Holocausto acreditam que ele foi descrito com precisão pela história" (ADL, 2014: 40). Além disso, "quase um terço daqueles que responderam que já ouviram falar do Holocausto pensam que ele foi ou um mito ou foi muito exagerado". (ADL, 2014: 41)

Desde os anos 1980 historiadores se dedicam a responder os argumentos negacionistas; e, atualmente já existe uma extensa historiografia especializada no chamado Negacionismo do Holocausto, com representantes principalmente dos Estados Unidos e da França. ${ }^{9}$ Essas duas historiografias, no entanto, pouco se conhecem.

Essa historiografia debate o Negacionismo do Holocausto sob múltiplas perspectivas teóricas e caracteriza-o a partir de diferentes problemas.

Há análises que consideram que o Negacionismo do Holocausto seja uma forma atualizada de antissemitismo. Outras analisam-no como um amálgama ideológico da extrema-direita contemporânea. Há aquelas que consideram o Negacionismo uma forma de mito político, o mito do complô (teoria da conspiração). Há, finalmente, aquelas análises que pensam o negacionismo como uma forma de pseudo-história. Neste texto, procuramos integrar essas análises. Assim, consideramos o Negacionismo do Holocausto um mito político que se consubstancia na forma de pseudo-história, isto é, esse mito procura revestir-se de autoridade intelectual e científica a partir da busca de legitimação historiográfica produzindo material que intenta simular o discurso acadêmico e científico. Assim, o Negacionismo do Holocausto, ao procurar minimizar os crimes nazistas, produz um projeto ideológico de resgate do nacional-socialismo e consegue unir diferentes facções da extrema-direita contemporânea, o que é viabilizado pelo antissemitismo implícito em sua visão conspiracionista, consubstanciado no "complô judaico internacional".

O Negacionismo surgiu logo após a II Guerra Mundial com os textos dos franceses Maurice Bardèche e de Paul Rassinier e do estadunidense Harry Elmer Barnes e se ampliou e se profissionalizou a partir de 1978 com a fundação de uma instituição nos Estados Unidos que, usando um nome que sugere ser uma respeitável instituição acadêmica de historiadores, se dedica a disseminar mundialmente o negacionismo, o antissemitismo e o conspiracionismo, o Institute for Historical Review (IHR). Em 1990, os negacionistas franceses criaram a Revue d'Histoire Negacioniste.

A partir de meados dos anos 1980, esse movimento político/ideológico ampliou-se de um pequeno público na França e nos Estados Unidos para o âmbito internacional devido a uma conjunção de fatores.

Em primeiro lugar, as transformações no capitalismo levaram à crise do industrialismo e o consequente enfraquecimento econômico e político da classe operária e seus sindicatos, precarizando suas con-

7 Cf. artigo no Daily Mail http://www.dailymail.co.uk/news/article-2462102/Amazon-sells-Holocaust-denial-anti-Semitic-white-supremacist-books.html

8 A ONG Anti-Difamation League ligada à comunidade judaica dos Estados Unidos publica anualmente um relatório sobre a situação mundial do antissemitismo.

9 Cf. as bibliografias listadas em http://web.york.cuny.edu/ drobnick/holbib1.html e em http://sicsa.huji.ac.il/denial.html\#Holocaust\%20 Denial:\%20A\%20Selected 
Artigos

dições materiais de existência. A cultura operária se enfraquece então diante do predomínio sucessivo da propaganda e da indústria do entretenimento. As classes médias, por sua vez, ficam ainda mais amedrontadas com a instabilidade das perspectivas presentes e futuras de acesso às benesses do capitalismo e, frequentemente, ficaram mais suscetíveis aos discursos alarmistas, xenófobos e autoritários.

Em segundo lugar, a ascensão ao poder de Ronald Reagan nos Estados Unidos e de Margareth Tatcher na Grã-Bretanha configuram a vitória da Nova Direita que realiza um ataque implacável ao estado do bem-estar social surgido no pós-guerra e que havia sido uma arma ideológica contra o socialismo representado pela União Soviética. O "fim do socialismo real" e a crise do movimento comunista internacional criaram um vácuo político rapidamente preenchido pelo neoliberalismo que defende o mercado como regulador privilegiado de toda a vida social e que ataca os direitos sociais e trabalhistas e o poder do Estado em regular os setores estratégicos e monopolistas (transportes, previdência, energia, comunicações etc.). Dessa forma, não só a esquerda tradicional torna-se cada vez mais frágil e isolada como também mostra-se incapaz de propor alternativas políticas à crise civilizatória que se ampliava.

Em terceiro lugar, no último quartel do século XX surgiu um movimento que se manifesta em uma nova religiosidade que influencia profundamente a cultura de massas (literatura, cinema, música etc.), atingindo em primeiro lugar a sensibilidade das classes médias e, posteriormente, das classes menos abastadas: o movimento New Age ${ }^{10}$. Entre suas influências, temos a valorização do "esoterismo ocidental"11 e sua influência crescente sobre a forma como esses grupos compreendem o mundo e, principalmente, a política. Diríamos que nos anos 1990 este movimento atinge amplos setores sociais por meio de sua incorporação pela indústria cultural, que edita milhares de livros, revistas etc. E que criará um novo tipo de produto cultural, a literatura esotérica e toda uma gama de serviços e produtos inspirados no chamado "esoterismo", ${ }^{12}$ vendidos em lojas especializadas.

Em quarto lugar, a partir dos anos 1980, diferentes grupos e partidos de extrema-direita surgem na Europa e conseguem algumas vitórias eleitorais significativas. Além disso, conseguem renovar seu discurso e aproximá-lo dos jovens, especialmente por intermédio da música e do futebol. É significativo que a partir deste período o movimento skinhead passa por um processo de aproximação com o movimento neonazista que leva a mídia a associar progressivamente o movimento skinhead ao nazismo. Não se deve esquecer que os skinheads, nos anos 1960, na Inglaterra, eram brancos e negros e curtiam uma variedade do reggae, o ska e que nem todos os skinheads atuais são neonazistas. ${ }^{13}$

Em quinto lugar, surge uma nova forma de divulgação de informações que revolucionou a forma como as pessoas se relacionam entre si, a Word Wide Web, mais conhecida como Internet e, principalmente para o que nos interessa aqui, uma nova forma de ativismo político, o ciberativismo. A "rede mundial de computadores" permite que essa nova extrema-direita fascista amplifique sua voz e se torne visível aos mais jovens e àqueles sem esperanças com a transformação política do mundo que os oprime. Além disso, permite

10 Definição da Enciclopédia Britannica online: "New Age movement, movement that spread through the occult and metaphysical religious communities in the 1970s and '80s. It looked forward to a "New Age" of love and light and offered a foretaste of the coming era through personal transformation and healing. The movement's strongest supporters were followers of modern esotericism, a religious perspective that is based on the acquisition of mystical knowledge and that has been popular in the West since the 2nd century ad, especially in the form of Gnosticism. Ancient Gnosticism was succeeded by various esoteric movements through the centuries, including Rosicrucianism in the 17th century and Freemasonry, theosophy, and ritual magic in the 19th and 20th centuries. Disponível em http://www.britannica.com/EBchecked/topic/704347/New-Age-movement

11 Utilizamos a definição de Esoterismo do Center for History of Hermetic Philosophy and Related Currents da Faculdade de Humanidades da Universidade de Amsterdan (Universiteit van Amsterdam): "The modern term "Western esotericism" is used as a general label for a great variety of religious currents and trends in Western culture - from Antiquity generally, and from the Renaissance to the present more in particular - characterized by their belief that true knowledge of God, the world, and man can only be attained by means of personal spiritual experience or inner enlightenment. The modern term "Western esotericism" is used as a general label for a great variety of religious currents and trends in Western culture - from Antiquity generally, and from the Renaissance to the present more in particular - characterized by their belief that true knowledge of God, the world, and man can only be attained by means of personal spiritual experience or inner enlightenment." Disponível em: http://www.amsterdamhermetica.nl/\#p/what-is-western-esotericism.html Acesso: 2 de junho de junho de 2013.

12 Esotérico aqui não se remete ao seu significado acadêmico, mas apenas ao seu sentido vulgar e popular.

13 Para maiores detalhes ver Salas (2006) e o filme This is England (Inglaterra, 2006). 
que se crie uma verdadeira rede virtual da extrema-direita, isto é, uma verdadeira nebulosa virtual em que se mantém minimamente ligados os inúmeros e diversos pontos da extrema-direita contemporânea.

Em último lugar, mas não menos importante, alguns pesquisadores consideram que, no final do século XX, as teorias conspiratórias (ou complô) ganharam dimensão mundial tornando-se megas-complôs (TAGUIEFF, 2006: 34) ou superconspirações (BARKUN, 2003: 6). A crescente importância da cultura conspiracionista aumenta também a demanda por abordagens mistificadoras da história que frequentemente estão a serviço de uma ideologia ${ }^{14}$, a maior parte das vezes da extrema-direita, a já mencionada pseudo-história.

As crises econômicas, política e social pelas quais a humanidade atravessa levou à criação das condições sociais e políticas para o surgimento de uma nova extrema-esquerda. Ou melhor, nos anos 1990 amadureceram as condições para que o processo de sua reorganização, que remete ao final dos anos 1960 e 1970, avance e torne visível a nova configuração da extrema-direita. Ela é diversificada em suas referências e origens e disseminada por todo o Ocidente. Esses elementos fazem parte de um processo que caracterizaria as profundas transformações ocorridas a partir do último quartel do século XX no Ocidente, que originaram diferentes teorias que sugerem que mesmo que as sociedades ocidentais ainda sejam industriais, "passaram por mudanças de tal alcance que não podem mais ser aceitas pelos velhos nomes nem estudadas no contexto de antigas teorias. Essas sociedades seriam agora, de várias maneiras, 'pós-industriais': 'pós-fordistas', 'pósmodernas', e mesmo 'pós-históricas"” (KUMAR, 1997: 9).

O Negacionismo do Holocausto insere-se na longa tradição do pensamento conspiracionista e antirrevolucionário inaugurado durante a Revolução Francesa por duas obras.

A primeira é Mémoires pour servir à l'bistoire du Jacobinisme, escrita pelo padre jesuíta Augustin Barruel (1741-1820), durante seu exílio em Londres, e publicada em Paris em 5 volumes, entre 1797 e $1799^{15}$. Rapidamente a obra foi traduzida para o inglês e publicada tanto em Nova York quanto em Londres, e já em 1798 já estava na $2^{\mathrm{a}}$ edição inglesa.

A segunda é Proofs of a Conspiracy Against all the Religions and Governments of Europe, carried on in the secret meetings of Freemasons, Illuminati and Reading Societies da autoria do físico e professor universitário John Robinson e publicada em Edinburgo em 1797 e ainda neste ano é publicada uma edição em Londres. No ano seguinte, uma terceira edição é publicada em Nova York, nos Estados Unidos. Ainda hoje, esses livros são reeditados e disponíbilizados em formato digital em livros, sites e blog conspiracionistas, tais como The Armagedon Cosnpiracy. ${ }^{16}$

Ambas as obras explicam a Revolução Francesa como uma grande conspiração organizada subterraneamente pela Maçonaria para destruir a ordem política e religiosa europeias.

O complô judaico é, segundo Girardet (1987: 25-34), uma das três grandes narrativas do complô elaboradas entre o final do século XVIII e início do século XX, quando foi editado pela primeira vez o livro “O protocolo dos Sábios de Sião”. Esse livro, forjado pela polícia política do regime czarista, foi rapidamente incorporado como arma de propaganda antissoviética e anti-bolchevique nos anos 1920 e 1930. Os nacionalsocialistas alemães transformam-no numa "prova irrefutável" de que os judeus são uma ameaça mundial ao mundo ocidental e a obra ainda hoje é reeditada em várias línguas e utilizada como uma espúria prova da existência de um complô judaico internacional.

Desse modo, a nova extrema-direita, a partir do final do século XX, atualiza essa perspectiva conspiracionista de sua visão de mundo ao articular sua filosofia da história maniqueísta com um típico exemplo de pseudo-história: o Negacionismo do Holocausto, chamado por seus adeptos de revisionismo. O Negacionismo do Holocausto é atualmente um dos principais elementos de coesão ideológica da grande diversidade dos grupos de extrema-direita, especialmente na França e nos Estados Unidos, e um elemento fundamental para a manutenção das forças de atração que mantém unida a nebulosa fascista contemporânea e ajuda a definir

14 “(...) o conceito de ideologia pode ser usado para se referir às maneiras como o sentido (significado) serve, em circunstâncias particulares, para estabelecer e sustentar relações de poder que são sistematicamente assimétricas -- que eu chamarei de 'relações de dominação'. Ideologia, falando de uma maneira mais ampla, é sentido a serviço do poder.” THOMPSON (1995: 21)

$15 \mathrm{O}$ site http://www.sacred-texts.com/sro/mhj/, por exemplo, disponibiliza trechos da obra de Barruel que recebeu um novo título, mais adequado ao momento: Code of the Illuminatti. Uma versão impressa de 2012 é vendida no site da Amazon.com pela editora Aziloth Books.

16 Disponível em http://armageddonconspiracy.co.uk/. Acesso em: 10 de setembro de 2014. 
Artigos

sua identidade. O Negacionismo do Holocausto não é uma perspectiva historiográfica legítima a se dedicar a revisar os postulados históricos do holocausto, mas sim um instrumento de ação ideológica a serviço de grupos políticos radicais em sua grande maioria de extrema-direita. Concordamos, assim, com Moraes (2011: 3), que considera um equívoco usar a terminologia historiográfica de revisionistas para designar aqueles que negam o Holocausto.

Burris, Smith \& Strahm (2000: 221-222), por exemplo, mapearam na Internet uma rede mundial da extrema-direita que agrega os "supremacistas brancos" em seus múltiplos subgrupos: Revisionistas do Holocausto; Teologia da Identidade Cristã; Neonazistas assumidos; Supremacistas brancos radicais; Supremacistas brancos moderados; Nacionalistas não estadunidenses; Skinheads racistas; Bandas, produtores, distribuidores e fanzines; e, editores de livros e produtores de memorabilia nazista. Estudando a extrema-direita francesa, o cientista político Camus (1997: 33) afirma que o Negacionismo do Holocausto "forma um cimento ideológico comum a todas as correntes da extrema-direita" francesa.

Os ideólogos negacionistas negam ou minimizam os efeitos do Holocausto e afirmam que o assassinato de milhões de judeus, ciganos, eslavos etc. é uma mentira criada e mantida pelos vencedores da II Guerra Mundial em estreita aliança com os judeus sionistas fundadores do Estado de Israel. Na verdade, o Negacionismo do Holocausto é outro lado da moeda do "complô judaico internacional" difundido desde o início do século XX pelo livro "O Protocolo dos Sábios de Sião”. Esse livro tornou-se peça de propaganda do antissemitismo desde então e, após a Segunda Guerra Mundial, também do antissionismo. No Brasil, foi traduzido pelo ideólogo integralista Gustavo Barroso e editado no início dos anos 1930. No final do século XX, a Editora Revisão se dedicou a publicar no Brasil livros negacionistas e a fazer propaganda sistemática do tema. Seu editor foi processado pela justiça do Rio Grande do Sul e, finalmente, condenado em última instância pelo Supremo Tribunal Federal (STF) em 2003. Atualmente, a editora não tem mais atividades legais em território nacional. (CRUZ, 1997).

Por mais que se publiquem artigos e livros que denunciam o caráter falso desse livro, os crentes da conspiração judaica internacional se recusam a aceitar os argumentos listados pelos historiadores para denunciar a obra. Certamente, isso se deve à lógica das teorias conspiratórias, que teria quatro princípios fundamentais: "nada acontece por acidente", "nada é o que parece", "tudo está conectado" e "tudo o que acontece é o resultado de vontades ocultas e malignas". (TAGUIEFF, 57 e BARKUN: 4).

15,4Conspiração" e as teorias conspiratórias elaboradas para explicar o atentado ao World Trade Center etc. Essa disseminação certamente colabora para a utilização do conspiracionismo pela extrema-direita como uma estratégia de disseminação de sua mensagem entre diferentes setores e classes sociais.

A Organização das Nações Unidas (ONU), em duas ocasiões, pelo menos, se posicionou claramente contra as tentativas de se negar a existência do Holocausto.

A Resolução 60/7 de $1^{\circ}$ de novembro de 2005 afirma que o Holocausto será sempre um “aviso a todas as pessoas dos perigos do ódio, da intolerância, do racismo e do preconceito" e que "rejeita qualquer negativa do Holocausto como evento histórico, seja no todo ou em parte"17

Dois anos depois, em 2007, a ONU reafirma a Resolução 60/7 e "condena sem nenhuma reserva qualquer negação do Holocausto”. Além disso, conclama os países membros a fazerem o mesmo. ${ }^{18}$

O tema do Negacionismo do Holocausto suscita uma férrea discussão em torno da questão da liberdade de expressão em geral e da posição dos historiadores em relação à criminalização do negacionismo.

Nos EUA, o Negacionismo do Holocausto não é considerado crime posto que há uma tendência de se usar a questão da liberdade de expressão quando se discute o direito dos negacionistas de se expressarem livremente, não só com suas publicações etc., mas também intervindo no debate público em jornais, revistas etc. A American Historical Association (AHA), principal organização dos historiadores estadunidenses em 1991, se posicionou contra o negacionismo (ADL, 2001). Os negacionistas usam muito bem essa prerrogativa constitucional para difundirem o negacionismo nos EUA e, a partir daí, disseminá-lo pelo mundo. A eficiên-

17 Cf. Organização das Nações Unidas. Resolução 60/07 de $1^{\circ}$ de novembro de 2005. Disponível em: http://www.un.org/cyberschoolbus/holocaust/N0548796.pdf

18 Cf. Organização das Nações Unidas. Resolution adopted by the UN General Assembly on Holocaust denial (A/RES/61/255, 26 January 2007). Acesso em: http://www.un.org/en/holocaustremembrance/docs/res61.shtml 
cia dessa estratégia é atestada pela já mencionada venda de seus livros no Amaz̧on.com, o maior site de venda de livros do mundo, pelo menos na versão original estadunidense.

No Brasil, desde a condenação pelo Supremo Tribunal Federal da Editora Revisão, que se dedicava a publicar livros negacionistas, definiu-se jurisprudência que considera racismo o Negacionismo do Holocausto, pois este foi então interpretado como antissemitismo.

Em vários países da Europa o Negacionismo do Holocausto é considerado crime. Vários negacionistas já foram condenados e encarcerados em diferentes países. Entretanto, muitos historiadores colocam-se contra essa legislação por considerá-la uma interferência ilegítima do Estado em questões que não lhe dizem respeito.

Em 2005, por exemplo, fundou-se na França a associação Liberté pour l' histoire para defender essa posição contra a judicialização da luta contra o negacionismo. ${ }^{19}$ Dois anos depois, o historiador francês Jacques Le Goof escreveu um artigo no jornal Libération no qual se colocou a favor da condenação e do combate ao negacionismo, mas sem sua judicialização: "Deixemos aos cuidados dos historiadores estabelecer os fatos. E, se uma situação histórica é complexa, se uma memória é atormentada, deixemos aos cuidados dos cidadãos a tarefa de formar uma opinião em função das informações." ${ }^{20}$

Concluindo, podemos afirmar que o Negacionismo do Holocausto é um tema que faz parte do horizonte político contemporâneo e certamente deve ser objeto da História do Tempo Presente, pois historicizar crítica e cientificamente o presente é uma abordagem necessária para se compreender essa ideologia. Finalmente, os historiadores que se dedicam à História Pública em suas diferentes dimensões tendo como referências éticas a defesa da democracia, dos direitos humanos e da ampliação dos direitos civis não podem deixar de incorporar os temas da pseudo-história e das teorias conspiratórias às suas pesquisas e cursos.

\section{Referências}

ADL. Holocaust Denial: an online guide to exposing and combating anti-semitic propaganda. 2001. Disponível em http://archive.adl.org/holocaust/print.html Acesso em 7 de agosto de 2014.

ADL. ADL Global 100. An index of anti-semitism. 2014. Disponível em http://global100.adl.org/public/ ADL-Global-100-Executive-Summary.pdf Acesso em: 12 de outubro de 2014

ALLCHIN, Douglas. Pseudohistory as pseudoscience. Science \& Education. 13: 179-195, 2004.

BARKUN, Michael. The culture of conspiracy: apocalyptic visions in contemporary America. Berkeley: University of California Press, 2003.

BURRIS, Val, SMITH, Emery, STRAHM, Ann. "White supremacists networks on the Internet". Sociological Focus, vol. 33, no 2, May 2000.

CAMUS, Jean-Yves. L'extrême droite aujourd'hui. Toulouse: Éditions Milan, 1996

CRUZ, Natália dos Reis. Negando a História: A Editora Revisão e o Neonazismo. Niterói:

Universidade Federal Fluminense, 1997. Dissertação de Mestrado.

GIRARDET, Raol. Mitos e mitologias politicas. São Paulo: Companhia das Letras, 1987.

GOODRICK-CLARKE, Nicholas. Sol negro: cultos arianos, nazismo esotérico e políticas de identidade. São Paulo: Madras, 2004.

KUMAR, Krishan. Da sociedade pós-industrial à pós-moderna: novas teorias sobre o mundo contemporâneo. Rio de Janeiro: Jorge Zahar, 1997.

LEGRAND, H. E., BOESE, Wayne E. Chariots of the Gods? and all that: pseudo-history in the classroom.

19 Cf. seu site oficial disponível em http://www.lph-asso.fr/

20 Cf. Le pouvoir de l'histoire. Libération, 19 de outubro de 2007. p. 2. 
Artigos

The History Teacher. Vol. 8, No. 3, May 1975, p. 359-370.

KRUGLYAKOV, Edward. Why pseudoscience is dangerous? Disponível em http://www.csicop.org/si/

MELLEUISH, Greg, SHEIKO, Konstantin, BROWN, Stephen. Pseudo history/Weird history: nationalism and the Internet. History Compass $7 / 6$ (2009): 1484-1495. Disponível em: http://mesosyn.com/his4-4. pdf

MORAES, Luís Edmundo de Souza. O negacionismo e o problema da legitimidade da escrita sobre o passado. Anais do XXVI Simpósio Nacional de História, ANPUH, São Paulo, junho 2011. Disponível em: http://www.snh2011.anpuh.org/resources/anais/14/1312810501 ARQUIVO ANPUH-2011-ARTIGO-Luis Edmundo-Moraes.pdf

ROLLAND, Denis. "Internet e história do Tempo Presente: estratégias de memória e mitologias políticas" In.: Tempo, vol. 8, n. 16, jan. 2004.

SALAS, Marco. Diário de um skinhead. São Paulo: Planeta, 2006.

SHERMER, Michael. Why people believe weird things: pseudoscience, superstition, and other confusions of our time. New York: Henry Holt and Company, 2002.

SHERMER, Michael, GRO BMAN, Alex. Denying history: who says the Holocaust never happened and why they say it ? Berkeley: University of California Press, 2009.

TAGUIEFF, Pierre-André. L'imaginaire du complot mondial: aspects d'un mythe moderne. Paris: Éditions Mille et Une Nuits, 2006.

. "Cens théories répondent à un besoin de sens". Conspiracy Watch. Disponível em http://www. conspiracywatch.info/Pierre-Andre-Taguieff-ces-theories-repondent-a-un-besoin-de-sens a301.htm

THOMPSON, John B. Ideologia e cultura moderna: teoria social crítica na era dos meios de comunicação de massa. Petrópolis: Vozes, 1995. 